\title{
Migration, translation, and transformation of western urban planning models
}

\author{
Pilar Maria Guerrieri*
}

\begin{abstract}
People, ideas, lifestyles, cultures, architecture and urban planning models have invariably traversed the world as a consequence of military compulsions, political goals, commercial motivations, or aspirational values. Western models in particular have spread widely, first through colonization and, recently, as a consequence of globalization. It is well-known that many cities around the world have been impacted by western urban planning models but, curiously no comprehensive comparative study of these influences has so far been attempted. This essay stems from 5 years of teaching and research in the field of urban history and presents a series of examples from non-western contexts such as India, China, Africa, South America, and elsewhere to showcase the direct or indirect impact of several western urban planning models. The aim is to analyse how differently these models, such as the English garden city, Le Corbusier's plan voisin concept, and Haussmann's plan for Paris have been adopted by a number of non-western cities and the degree to which they have been transformed by local contexts. Indeed, frequently, the original concept of the exported model has been completely modified. The essay also identifies those western urban models which have spread most widely. There are, indeed, a series of western models which have proved more popular than others and it is worth attempting to understand why they have proved to be so.
\end{abstract}

Keywords: Urban, Planning, Migration, Western models, Cultural exchange

\section{Introduction}

Migration today is at the centre of political, economic, social, and even architectural debates. Migration processes ${ }^{1}$ have occurred in all epochs and in different cultures. It has occurred as a consequence of military motivation, commercial reasons, political goals, or aspirational dreams. The process of the migration of ideas has been greatly and progressively expedited during the past century as a consequence of increasingly convenient and progressively rapid means of transportation. Today, in the field of architecture, with the spread of modern technology and the facilities available to export materials from one country to another, we are witness to vastly accelerated processes of the migration of architectures and urban planning models.

The aim of this essay is to explore the incredible and pervasive impact of western urban architectural planning

*Correspondence: pilar.guerrieri@polimi.it

Politecnico di Milano, Via Leonardo da Vinci 32, 20133 Milan, Italy models in non-western contexts. Here I have selected, a few among many, particularly interesting western urban planning models which have spread around the world and shaped its urban landscapes. There are indeed certain specific western models which have been adopted most frequently, leaving a visible and durable imprint on the urban history of non-western contexts.

Western civilization has been particularly active in formulating urban planning models and ideas available for export, and western countries have played an active role in the exportation processes. The model adopted needed to suit the relevant political, social, and economic context, and there are certain contexts which have been more propitious and welcoming than others in receiving the imported prototypes.

Models, i.e. specific solutions, used in a certain period to resolve a particular issue, migrated from one place

\footnotetext{
${ }^{1}$ See Rochon (1998).
} in this article are included in the article's Creative Commons licence, unless indicated otherwise in a credit line to the material. If material is not included in the article's Creative Commons licence and your intended use is not permitted by statutory regulation or exceeds the permitted use, you will need to obtain permission directly from the copyright holder. To view a copy of this licence, visit http://creativeco mmons.org/licenses/by/4.0/. 
to another but not necessarily for the same reason. Frequently a particular model was modified and translated according to the requirements of the place to which it had been transported.

Sometimes the local people and their lifestyle required the imported planning model to be so drastically modified that the original concept became unrecognizable. At other times, ideal models are utilized as utopias without really taking into account the original context, and even these types of adaptations, through local pressure and requirement, get transformed over time. On yet other occasions certain models are combined with others, generating new solutions to urban planning.

It is, of course, for lack of space, impossible to extensively discuss western urban model migration and therefore the attempt here is to selectively explore the subject and provide some guidelines for future research. It is a field which, taken as a whole, has not so far been much explored and therefore it will be extremely useful for urban planners, architects, and theorists to devote critical thought to it and elaborate suitable bottom-up solutions rather than top-down ones.

\section{Theoretical framework}

The literature available on the impact of western urban models in non-western contexts is very scattered, and no comprehensive, comparative analysis exists on this area; indeed, there has not even been any attempt made in this direction. There are innumerable general books on western urban development, some focused largely on the West, such as Morris, ${ }^{2}$ and others somewhat more open to a dialogue with 'the other', such as Kostov. ${ }^{3}$ Kostov does not include 'the other' in the brief appendix at the end of the book as Morris does, but he articulates a much richer understanding of how urban typologies have declined in sundry contexts. Nevertheless, these generic books on urban history are still, by and large, western focused.

There are however many books relating to each nonwestern context which attempt to analyse the local urban scenario. For example, a very well documented description of the Japanese urban context and Japanese planning processes is Sorensen, ${ }^{4}$ tracing the patterns of development of Japanese cities since the establishment of the castle towns of the Tokugawa period. On Africa,

\footnotetext{
${ }^{2}$ See Morris (1994). The book has very brief appendices of one to three pages each, on urban planning in China, Japan, India, and Indonesia.

3 See Kostov (1991).

4 The urbanization of modern Japan began during the Meiji period (18681912), but Japan had a long history of urbanization prior to that during the Tokugawa period, 1600-1868. (Sorensen (2006).
}

Bickford-Smith, ${ }^{5}$ and Demissie, ${ }^{6}$ provide a broad overview on the impact of western models on the African continent. There is an interesting book, ${ }^{7}$ which specifically focuses on Cape Town city with an accurate analysis of the Dutch influence and the impact of the British Garden City movement. Similarly, King's, ${ }^{8}$ and Legg's ${ }^{9}$ provide a similar overview of the Indian urban context. Both books focus on the impact that British colonialism had on Indian urban settlements and how the latter have been unrecognizably modified.

There are general books on patterns and trends of urbanization in broader areas, such as Elsheshtawy, ${ }^{10}$ on northern Africa and the Middle East and Diaz, ${ }^{11}$ on Brazil; and more specific books, which showcase the impact of western models on specific urban realities.

On the latter, see, for example, ${ }^{12}$ by Rotbard, which is an interesting book comprehensibly explaining the contradictions and political implications of the imported Bauhaus Style in Tel Aviv; or the book by Denison and Ren, ${ }^{13}$ which discusses the impact on the development of that Chinese city of its interactions with western culture.

Analyses and books on specific urban realities and the impact of western culture with greater or lesser detail are available for many countries, but with very few on comparative studies such as that by Bigon and Katz. ${ }^{14}$ The authors attempt to analyse the specific Garden City urban model and the ways in which it has spread to different parts of the world, showcasing how it has been translated and adapted in each different context.

A part of the literature which interestingly explored the relationship between cultures and power, even if frequently beyond urban studies, is connected with the post-colonial debates and discourse. Studies such as Said's (1978) and Bhabha (1995), and even Spivak's (1999) have provided important background information, which

\footnotetext{
${ }^{5}$ It provides a detailed description of the anglicization of the cities of Cape Town, Durban, and Johannesburg; and brief mention of the use of the Western Garden City model and City Beautiful principles (pp 155-156). See Bickford-Smith (2016).

${ }^{6}$ It analyses a very broad and diverse spectrum of African architecture and urbanization, including the Italian colonization of Libya, British African cities, and colonial architecture in Angola. See Demissie (2017).

7 See Coetzer (2013).

8 See King (2012).

9 See Legg (2007)

10 The books focus on the transformation of the cities of Algiers, Baghdad, and Sana'a, and on Cairo and Dubai's past and contemporary developments, specifically taking account of a colonial and postcolonial perspective. See Elsheshtawy (2004)

11 The book showcases fascinating plans and paintings of the first colonial settlements in Brazil. See Diaz (2004).

12 See Rotbard (2005).

13 See Denison and Ren (2006).

14 See Bigon and Katz (2017).
} 
has added a wider critical perspective to the urban studies that followed.

The extant literature lacks a critical and comparative overview of the migration of western urban models around the world and there is no attempt to identify the most successful of these and what imbues them with that strength.

\section{Research methodology}

This essay is the result of many years of comparative urban studies on several non-western contexts coupled with the outcome of reflections and analysis in class with students of urban history and through specific studies in libraries and archives. The study developed after redrawing many plans of cities around the world and acquiring a deep understanding of their development. Some of the sources used are secondary but the comparative and critical process presented is entirely original. The study has first looked into each context-such as India, China, the Middle East, Africa, South America, and Australiaand analysed its specific urban histories. Only after these analyses has it been possible to proceed with a selection of most relevant examples. The final comparative phase is particularly relevant because it has provided me with the opportunity to identify and highlight specific contexts in which western models have been adopted and distinguish repetitive modus operandi, categorize those which have been used more frequently than others, understand the reasons why certain models have been adopted and which modification occurred in the migratory process, isolate standard application of urban patterns and the instrumentalization of the latter. The following paragraphs showcase the results of the research and highlight the western urban models ${ }^{15}$ which have been identified as some of the most adopted and have widely spread in non-western contexts.

\section{Data analysis}

\section{The roman castrum in Timgad and Jerash}

One of the larger ancient western empires, which framed rules for urban planning and exported them, was most certainly the Roman Empire, which especially expanded during the Imperial period around $117 \mathrm{CE}$.

The Romans conquered extensive territory and designed cities from France to Libya, all the way to Jordan. Their characteristic grid model with elements of the Roman castrum is to be found in many cities far beyond Italy. The Roman city model derived much inspiration

\footnotetext{
${ }^{15}$ It is important to note that the Western urban models have been selected as the focus of this essay but equally interesting would be to develop a study on Asian urban models, such as the application of fengshui principles, and their wide spread use throughout Asia.
}

from the planned Greek polis, such as Miletus on the mainland or Selinunte in the Magna Grecia area, ${ }^{16}$ and then elaborated a standard model to be applied in all the conquered territories.

Sometimes the Roman layer is merely a grid footprint, as in the case of the Italian city of Turin. Elsewhere, as in the city of Lucca, the old ruins of the Roman amphitheatre are reimagined as a contemporary square, where the amphitheatre's old wall is reused as a support for the new buildings. In other instances, as in southern France, the Roman remains are a scattered counterpoint of the contemporary urban pattern, as for example the Roman theatre of Orange.

In the non-western context of northern Africa, many cities have a Roman origin but have completely transformed contemporary urban realities. Among the bestknown cities from Morocco to Egypt are Alessandria d'Egitto, Edfu, Thebes, Tripoli, Bengazi, Algiers, Tangiers, Annaba, Susa, Sabratah, and others.

The scattered Roman ruins in Libya were frequently used for political purposes by Mussolini during the Fascist period. ${ }^{17}$ Breviglieri village, for example, one of the many small settlements designed at that time, was imagined starting with the rediscovery of a Roman arch.

Besides, the Timgad archaeological site in Algeria is one of the best-preserved ruins of an ancient Roman settlement: the cardo and decumanus, the aqueduct system, the fountains, thermal baths, theatre, and forum are still visible as a footprint on the land.

Similarly, in the Middle East, many cities have a Roman origin, such as Efeso, Smyrna, Aqaba, Jerash, and many others. In several instances, the Roman pattern has largely disappeared, overlapping with more contemporary developments, but in some, such as Jerash in Jordan, ${ }^{18}$ the Roman city has been left untouched and nothing has been built over it or destroyed, which provides us with an opportunity to observe the incredible original Roman remains.

The grid plan is probably the crucial element of Roman urban planning, and although the Greeks had in the seventh century CE already used the grid, ${ }^{19}$ they never made such an extensive use of it as did the Roman empire, transforming it into a genuinely replicable prototype. Besides, we must remember that the grid pattern of the Romans was primarily developed as a military tool ${ }^{20}$ and not as a commercial one.

\footnotetext{
16 'The grid plan used by the Romans was not precisely that of the Greeks. It was an adjustment of the plan used by the Greek traders to the demands of a Roman order', in Stanislawski (1946).

17 See Woolbert (1932).

18 See Aulama (1994)

19 See Owens (1991).

${ }^{20}$ See MacDonald (1986).
} 
In ancient western history, the Roman model, and its spread in a number of countries around the Mediterranean sea, has been one of the most important examples of model migration. Even if replicability and discernible recognizability are the principal characteristics of a model, as we have seen, models are never rigid elements, and become greatly transformed in the process and over time. Unfortunately, the Roman remains are today often overlapped by other developments, or preserved as a simple ruin, and therefore it is very difficult to understand the degree to which the original Roman settlement hybridized itself with the local culture.

\section{The Spanish model in Latin America}

European colonization has undoubtedly had an incredible impact on most non-western countries, considering that over 80 per cent of the world was colonized by different actors in different periods of time: the Spanish, Portuguese, Dutch, Germans, British, French, and Italians have each exported not only architecture but also urban plans and urban visions from the fifteenth to the twentieth centuries.

Among the earlier colonizers, the Spanish colonized central America and part of South America, massacring the Aztec-Inca population and destroying their legacy. Spanish colonization brought a very different urban model in loco. ${ }^{21}$ Apart from ushering in a cultural influence, the Spanish undertook urban colonization of the territory and towns from the very outset and became an instrument of political control.

The colonial operation began in the fifteenth-sixteenth century when the old Spanish cities in the motherland were still quite basic in terms of organic road patterns, (tight) roads, and building techniques. This was different in the new Spanish territories in 1526, well before the Industrial revolution, Philip II decided to adopt 'modern' planning. First, he proposed the application of the Laws of the Indies, a set of guidelines for design inspired by the Italian Leon Battista Alberti, including strict rules for planning new cities. ${ }^{22}$ The manual necessarily brought about standardization of the model applied, which is that which is to be seen today in the footprints of most cities of the former New Spain colonies. The plans affected by the Spanish model ranges from Lima, Cuzco, Buenos

\footnotetext{
21 'During the reign of Philip II (1556-1598) a number of regulations with more specificity were drawn up for the new settlements. These were the instruments for the building codes for the human settlements during the colonial period in Ibero-America. These regulations were called Ordinances of Discovery, New Settlements and Pacification and were decreed by Philip II in the Segovia Woods on July 13th, 1573.' Rodriguez (2005), pp 48-49.

22 'In the sixteenth century the revival of Vitruvius and the work of the Italian Renaissance planners affect city building in the New World.' See Morse (1962).
}

Aires, El Salvador, Guadalajara, and Mexico City. In particular, we read that 'Mexico City had already become the largest city in the Spanish World, and it was unique among great cities of its time' 'in that it was an unfortified metropolis, occupying a plan which shows close affinities to the ideal town plan of Italian architectural theory.' ${ }^{23}$ The first evidently Italian element is the use of the great piazza, i.e. plaza mayor, and the grid pattern ${ }^{24}$ which irradiates from the square: 'the Renaissance left its clear mark upon the disposition and construction of the civic centre, the decisive feature of the master grid was the subordination of the streets to a central square. ${ }^{25}$ There are some cities where the plaza mayor has actually disappeared but in many other instances the square is still very visible and in use as a religious centre, socializing space, a ceremonial centre, a marketplace, and a garden park: 'Latin America encouraged the functional diversity of the space. $^{, 6}$ The most interesting aspect is the direct colonization and urbanization of new Spain by the Spanish crown, but also the indirect inspiration and application of the Italian urban model. In addition, the vast number of churches and convents, spread as major public buildings within the urban pattern, are another sign of the strong and subtle hybridization that occurs among cultures.

\section{Axes and vistas from France to Australia}

The formalization of the idea of a beautiful city: wide roads and paths, continuing connected street frontage, and vistas is best illustrated by the celebrated Haussmann's Plan for Paris ${ }^{27}$ developed between 1853 and 1870. The Paris model was seen as ground-breaking by many western planners. First and foremost, by Daniel Burnham when, together with Edward H. Bennett, designing the Chicago plan in 1909, he developed and consolidated the concept of the 'city beautiful.' ${ }^{28}$ The Haussmann and Burnham visions for the city are very aligned even if they have been utilized in two entirely different contexts. The purpose of Haussmann's plan for Paris was to demolish the old medieval city and build a new modern one with wide avenues, parks, and squares, sewers, fountains, and aqueducts. Burnham, by contrast, while imagining new wider arterial roads to relieve traffic congestion and beautifying the fast-growing city, did not

\footnotetext{
${ }^{23}$ See Morse (1962).

24 See Morse (1962).

25 Ibid, p 321.

26 See Gade (1976).

27 The Haussmann plan was very innovative for the time when it was implemented and included many other aspects, such as green parks, improvement of the sewage and drainage system, continuing connected street frontage, and the like. See Saalman (1971).

28 See Wilson (1994).
} 
have to cope with a very ancient and valuable historical core.

The concept of a vista has however been crucial to both plans, and this was re-adopted by many European and American capitals, ${ }^{29}$ and also other non-western settlements. One of the best-known instances is the plan for the new capital of Canberra in Australia designed by W.B. Griffin in 1911 which clearly emulated the radical Burnham Chicago plan principles. ${ }^{30}$ The Griffin Legacy report makes it very clear that 'The Griffin Plan for Canberra provides a lens through which we can view the emerging science of Town Planning in the early twentieth century. One of Griffin's major achievements lies in his assembly of diverse town planning theories and practical prototypes ... Undoubtedly it is a master work in the City Beautiful style. ${ }^{31}$ Moreover, the city beautiful model is not the only western model adopted: 'Composed on a cross-axial scheme, the plan fused geometric reason with picturesque naturalism. Although indebted to City Beautiful ideals and more domesticated garden city planning principles, the Griffin's reliance upon geometry as an organizing device more profoundly registered their conviction that the natural world was the essential source for design.' It is interesting that in Australia it was the American architect Griffin who directly imported the western urban models and adjusted them to the local reality.

Comparably, the plan of New Delhi, elaborated in the same year 1911-1912 by the British architects Edwin Lutyens and Herbert Baker, suggests a similar intricate composition of axis and roundabout, ${ }^{32}$ but the use of them is completely different from the previous contexts. In Delhi, the imported city beautiful model was adopted to further the segregation between the local population and the colonialists.

The idea of 'beauty', 'beautiful', 'beautification' has undoubtedly attracted many planners, sometimes going hand in hand with the garden city model.

\section{Translation of the garden city model}

The idea of a garden city model was proposed by E. How$\operatorname{ard}^{33}$ and was first implemented in Letchworth garden city by Barry Parker and Raymond Unwin in 1905. The garden city model originally had to be an answer to the growing industrial city of London, to the squalor and poverty of its urban life, and a solution to its sustainable expansion. The idea was to develop a 'Social City' and

\footnotetext{
${ }^{29}$ See the Mc Millan plan for Washington DC, 1902.

30 See Vernon (Vernon 2006).

${ }^{31}$ See Vernon (2004), p. 32.

32 See Volwashsen (2002).

${ }^{33}$ See Buder (1990).
}

'establish a prototype Garden City as a "Town-Country Magnet" offering the advantages of both town and country life with none of the disadvantages. ${ }^{34}$ The garden city model has subsequently been exported to different parts of the world directly by the British colonial power or by other colonial enterprises. The UK has exported the garden city model to its colonies, and India is one of the most relevant and best-known instances. The new capital of New Delhi, designed by Edwin Lutyens and Herbert Baker in 1911, is clearly inspired by the garden city principles, especially in the housing and garden patterns. The large green areas around each bungalow was a guarantee of a healthy and congenial life for the British in the new colonial capital. However, by doing this in India the original 'social' meaning of garden city imagined by Howard completely transformed itself: the original social purpose has changed into a logic of imposition of power. The new airy and spacious design of New Delhi had nothing to do with the traditional organic and compacted Mughal city of Shahjahanabad (old Delhi); indeed, the garden city model became a way to further a separation/segregation between the indigenous settlements and the colonial ones.

The garden city concept also reached other non-western contexts, indirectly through French colonial rule, all the way to the French colony of Morocco. The French had early adopted the garden city as a prototype for a few Paris suburbs such as Suresnes (1919) and Les Lilas ${ }^{35}$ (1921-1923), and then they largely implemented it in the design of the Moroccan ville nouvelle during the French Protectorate from 1912 to 1956. In particular, the term cité-jardin had been largely used to denote certain residential quarters within the ville nouvelles of Casablanca, Rabat, Fez, and Marrakech, and only in few instances to indicate the entire ville nouvelle. Like the British in India, the French in northern Africa adopted the garden city with a very different meaning and purpose from the original British Howardian idea. 'The cité-jardins that flourished in Morocco under the French Protectorate showed exemplar evidence of the semantic misappropriation of the original idea. ${ }^{36}$ Indeed, the new Maroccan cite-jardins were far from being autonomous cities/satellite cities as in Howard's conception but principally housing estates intended for expatriates'; an area of the town itself. They had only very limited public amenities - schools, places

\footnotetext{
${ }^{34}$ See Miller (1983).

35 'The originality of new French towns lies in their conception: they are integrated in an urban region and are not 'cities in the country' in the garden city tradition. They are part of a regional development pattern.' In: Merlin (1980).

36 Charlotte Jelidi, 'Symbolic Usage of the Garden City concept during the French Protectorate in Morocco, in Bigon and Katz (2017), pp 35-49.
} 
of worship, and few public parks - in comparison to the English garden cities but fully embraced the idea of abundant greenery. As in India, city planning had become an active tool of segregation between the local people and colonizers.

The garden city is one of those urban models which has been widely adopted in different parts of the world for different purposes in different periods of time, and not just by the colonial enterprises. For instance, in the US, during the 1950s, the garden city idea was distorted into urban sprawl: low-density development outside the urban core entailing incredible land consumption and fragmentation.

In today's more recent conditions, garden city principles suit the new ecological pressure and can be seen applied and reinterpreted in contemporary cities of China, such as the Chengdu ${ }^{37}$ garden city renewal plan, where 'the goal is that every 300 metres you see green'. These latter cases were greatly modified and distorted in the migration process and have clearly little to do with the original British model.

\section{The spread of Le Corbusier principles}

Le Corbusier was a very unique and original urban planner and architect of the twentieth century. He had a very clear vision on what architecture and urban planning should be, and sought to apply top-down his ideas in each context where he had the opportunity to work. Unlike the other instances we have so far analysed, the spread of Le Corbusier planning ideas and models across different parts of the world was largely determined by himself and not for any colonial or commercial reason. The concepts of tabula rasa, living machine, unite d'habitation, his five points of architecture and modernism, were exported by him, and also by his pupils, to virtually every corner of the world. He was undoubtedly a remarkable innovator in terms of urban planning and it is sufficient to cite his plan voisin for Paris (1925) or radiant city (1930) to understand the kind of transformation he imagined for the traditional European city just few decades after the Industrial revolution. He exported his ideas on urban planning throughout the world, designing plans for Moscow, Sao Paulo, Buenos Aires, ${ }^{38}$ Algeria, Addis Ababa, ${ }^{39}$ and others. All the plans, even if not realized, are a representation of his utopian city model. Le Corbusier had only one opportunity to attempt to realize his utopia in Chandigarh, India, in $1956,{ }^{40}$ where he designed the overall plan for the new capital of Punjab

\footnotetext{
${ }^{37}$ See Kuo (2017).

${ }^{38}$ See Baez (2005), pp 100-111.

${ }^{39}$ Sobin (1994).
}

and the brutalist buildings of the capitol complex. The Chandigarh plan was created from a tabula rasa, apart from a few pre-existent villages which could not be removed. Most of the housing was designed by an Indian team guided by Le Corbusier's collaborators Maxwell Fry, Jane Drew, and Pierre Jeanneret. The function of living in Chandigarh occupies a primary place in the planning and has been organized into a system of sectors based on the concept of a neighbourhood unit. Each sector is a selfsufficient unit equipped with shops, a school, health centres, and places of recreation; it can accommodate 3000 to 20,000 people depending upon the sizes of the plots. The buildings have, by and large, two or three floors, with gardens in front and at the back of the plot, often built with inexpensive exposed or plastered bricks. It is very interesting to notice the discrepancy between the original high-rise building blocks imagined for the ville radieuse and the actual human scale, low-rise, low-density housing utilized in Chandigarh.

Paradoxically, the le Corbusier urban model has become such an inspiration for other architects that his utopian radiant city was realized even better and more faithfully by his pupils Lucio Costa and Oscar Niemeyer in their plan for Brasilia in $1960 .^{41}$ The latter urban plan, designed from scratch using two principal monumental residential axes as a starting point, is very much a realization of Le Corbusier's dream of what a modern city should look like: 'Brasilia is a ville radieuse vert." ${ }^{42}$ One monumental axis was designed for political and administrative activities and included a series of oversized brutalist institutional buildings, while the residential axis is constituted of 96 reinforced concrete superblocks organized in self-contained and self-sufficient neighbourhoods. Interestingly, actually the super blocks in Brasilia designed by the two Brazilian architects are much closer to the original idea of unite d'habitation than the twofloor brick lane houses which characterize most of Le Corbusier's Chandigarh plan.

It is clear from the Indian and Brazilian examples that the migration of an urban model is not necessarily linear but instead is often unpredictable, guided by undisclosed and subtle dynamics.

\section{Worldwide zoning phenomena}

The trend of a contemporary, rapidly-growing metropolis is to segregate and separate single interventions in the urban pattern, imaging the city as a collage of distinct pieces largely disconnected from one another. The

\footnotetext{
${ }^{40}$ See Corbusier et al. (2014).

41 See Carvalho and Brasilia (1991).

42 Silva and Silva (1987), p 258.
} 
zoning ${ }^{43}$ method of planning is again a model of urbanization which can be considered to be a product of European culture. In France, Germany, and the UK the first pseudo-zoning method was invented to prevent polluting industries to be built in residential areas, but it was in Germany alone that the modern zoning concept was developed in the late nineteenth century. From there it spread extensively, first to America, and then worldwide. It is important to note that most ancient cities were classified in different land types, for example in China and the Roman Empire, but only during the industrial revolution was there a rapid enforcement of urban regulations and zoning became a standard procedure in urban planning. Functional zoning ${ }^{44}$ is a rigid way of segregating functions and keeping different purposes, such as residence, commercial and industrial use, all separated from one another, and nowadays this principle has been extensively applied to many masterplans around the world. Any plan, from south America to Africa, to India and Australia, has adopted the zoning plan from the 1950s onwards. You just have to open online any masterplan of most of the cities around the world to see how widespread the zoning principles have become.

That notwithstanding, zoning is not always the most suitable model. Often, mixed use has proved to be a better solution: reducing the dependence on cars and the environmental impact of these, allowing people to live where they can also shop, work, etc., mixed housing to increase affordability, the amalgam creating an urban environment active at all hours, optimum utilization of the infrastructure, and the like.

The megacity of Delhi is one of the many instances where zoning was applied-since 1962, the first masterplan after Independence, till 2021, the latest plan-and there it has clearly not proven to function as intended. Notwithstanding the indication in the masterplan that one particular area had to be solely residential or commercial, in reality, looking deeper into the true status of that area, we discover that it does not support a single function but many. The local area plan experiment ${ }^{45}$ of 2011 has actually confirmed that the areas which the masterplan dictated were to be mono-functional are in

\footnotetext{
${ }^{43}$ See Amnon (2017); see also the definition of zoning in https://en.wikipedia. org/wiki/Zoning.

${ }^{44}$ Functional zoning is the most prevalent form, other types are: formbased (define zones according to their physical characteristics), intensity zoning (defines land use zones by the level of permitted intensity), and incentive zoning (considered as part of a revitalization or development plan).

45 The Local Area Plan is an experiment undertaken during the past 10 years where several institutions in Delhi were involved in re-mapping the city areas to understand how the city plan has actually been changed or to what extent the zoning was actually applied. They discovered that the masterplan's rules were universally being flouted.
}

reality multifunctional because people acted bottom-up, changing their own context to meet their requirements. Delhi is only one of many urban contexts where rigid zoning has been imposed top-down and it has not been effective in resolving meaningful local issues.

Besides functional separation, developing gated communities appears to be the ultimate frontier of further contemporary segregation. An increasing number of people want to keep themselves safe, want to protect their privileges, in a world where differences between the rich and the poor are becoming more glaring, and strengthening the need of the well-to-do to segregate themselves. Gated communities developed as a trend in American urban planning, where the zoning approach was most commonly based on the assumption of exclusivity, and it spread as a need in difficult environments like those of Brazil, Africa, and south America.

\section{Conclusions}

This essay has attempted to emphasize the connections between selected urban planning models in different parts of the world, highlighting those which could be identified as being 'stronger.' One reason why these particular models may be perceived to be stronger is because they have been widely disseminated. It clearly emerged from the study that the Roman castrum was exported around the Mediterranean Sea, the Spanish grid around Latin America, the garden city and Haussmann principles in most of the colonial territories, not to mention the Le Corbusier impact around the world and the worldwide spread of zoning.

The basic ideas behind each of these models were very clear and comprehensible and therefore they were easier to copy and replicate. Indeed, the roman castrum, the Spanish model, and the le Corbusier Plan voisin share the grid principle, which in itself is a very flexible element. Similarly, zoning's functional simplification has very intuitive principles which comply with the western idea of organization and order.

Interestingly, the study revealed that the urban models didn't just migrate to different locations but were also greatly modified in the process. For instance, the garden city model was not identical in the UK, Morocco, or in India but was adapted in accordance with the requirements of the time, purpose, and context in which it had been adopted.

This aspect of adaptability, which may appear to be marginal, is instead crucial. It helps us to understand why these models may have emerged stronger than the others: their strength and widespread use partly lies in their inbuilt capacity for adaptation. A model is not strong just because it is striking and useful but when it demonstrates the ability to serve very different purposes and to be able 
to resist and adapt to time and contexts. Besides, each of these urban planning models, even if they have hybridized themselves in the process of migration, is still very recognizable in its basic principles, leaving a very significant legacy behind and becoming a milestone in contemporary urban planning. It is clear that the aspects of integrity and change of urban models show an interesting local/global interplay between local transformation and global spread.

The study clearly highlights that there is a grounded level of analysis which keeps a careful account of the relationship between design patterns and the specific culture which adopted and spread them, and a more general and abstract level of investigation of patterns such as urban form, i.e. grid, axes. Both these facets are important in better understanding the phenomenon of urban planning model migration. Urban planning models have always migrated across the world for different reasons, sometimes through the will of a ruling power, at other times a single individual who had been responsible for spreading it, or just the desire of a nation to take inspiration from another country. The migration processes of models, not just the urban planning ones, has directly or indirectly been always strongly related to a power/culture relation.

Even among western models, as we have seen, not all have equally spread, but it is not necessarily the case that particular models are good or successful just because they have been widely adopted. Sometimes a deficient model can be approved top-down for political reasons, as in the case of the zoning solution. Therefore, a critical understanding of these subtle migratory processes is necessary to achieve a truly sustainable planning regime. Certainly, bottom-up designs, where models are generated locally and developed by using the context as a starting point, have great potential to be successful because they have the people, the economy, the real issues as the criteria. It is important to remember however that it is not wrong to use an imported model as long as is done critically. See, for example, Patrick Geddes, a planner, who wonderfully attempted to apply the bottom-up principle even for the major Tel Aviv (1925) plan which he designed with his home town garden city as a major reference.

Adopting a critical approach to urban design is not necessarily a guarantee of success of one specific urban model but it certainly has greater prospects of being efficacious in the context in which it is adopted because it is confronting real and existing issues. The western models worked, and not invariably, in the contexts where they were first adopted because they were resorted to in order to resolve particular issues at a particular moment in time. Unfortunately, when they were applied top-down in other contexts or in other periods of time, without any consideration of local requirements they did not prove to be the most suitable options.

This essay has sought to encourage readers to think further about how we can overcome our baggage of learning and to be able to rethink urban planning and urban models from the intricate global connection's perspective, never forgetting the point of view of the context and the local reality where new planning is to be realized. Comparative studies across different realities are an eye-opener, not just because they develop an awareness of power/cultural dynamics relating urban planning but also because, highlighting links and connections, they allow a cross-cultural understanding of urban forms and their everlasting value.

\section{Acknowledgements}

Warm thanks to my students undertaking courses in Urban History, Historic Settlements, and History of Architecture at the GD Goenka University in Delhi, India, and in Politecnico di Milano, Milan, Italy who since 2015 have invariably been an inspiration and continually forced me to delve deeper into the subject when preparing my lectures. A special 'Thank you!' to Profs. Paolo Ceccarelli and A.G. Krishna Menon who have always been there to give my thinking a fillip.

\section{Authors' contributions}

Pilar Maria Guerrieri is the sole author. The author read and approved the final manuscript.

\section{Authors' information}

Dr Pilar Maria Guerrieri has lived between Milan, London, and Delhi for the past 9 years. She holds a Ph.D. with honours in 'Architectural Composition' from Politecnico di Milano in association with the Indian National Trust for Art and Cultural Heritage in Delhi and Westminster University in London. She has been extensively studying the city of Delhi pre- and post- Independence and, in particular, the impact of British and American cultures on its urban planning and architecture. She has been researching European and Indian cultures, the development of megacities, and the effects of cultural exchanges, exploring the meaning of terms such as 'tradition,',legacies' and 'heritage'. Pilar, since she completed her PhD has been teaching. She has been Associate Professor in 'History of Architecture and Human Settlements' in Delhi at the Italian-Indian GD Goenka University, branch of Politecnico di Milano in India, and is now Adjunct Professor in 'History of Architecture' and 'Urban History' at Politecnico di Milano in Italy. Her work has been published in several international journals and she has participated at several national and international conferences. She is the author of the book Maps of Delhi (Guerrieri 2017) and Guerrieri (2018).

\section{Funding}

Not applicable.

\section{Availability of data and materials}

The data used and analysed during the current study are available with the author.

Ethics approval and consent to participate

No human, animal or plants data are included.

\section{Consent for publication}

Not applicable.

\section{Competing interests}

The author declares no competing interests.

Received: 17 October 2019 Accepted: 17 January 2020 Published online: 27 January 2020 


\section{References}

Architettura nelle Colonie Italiane (1992) in 'Rassegna', XIV, 52/3

Aulama M (1994) Jerash: a unique example of a Roman city. Brepols Publishers, Turnhout

Baez E (2005) Cruelty and Utopia: cities and landscapes of latin America. Princeton Architectural Press, Princeton, pp 100-111

Bhabha H (1995) Location of culture. Routledge, London

Bickford-Smith V (2016) The emergence of the south African metropolis. Cambridge University Press, Cambridge

Bigon L, Katz Y (2017) Garden cities and colonial planning: transnationality and urban ideas in Africa and Palestine. Manchester University Press, Manchester

Buder S (1990) Visionaries and planners: the garden city movement and the modern community. Oxford University Press, Oxford

Coetzer N (2013) Building apartheid: on architecture and order in imperial cape town. Routledge, New York

Corbusier L, Jeanneret P, Seguin P (2014) Chandigarh, India. Gallerie Patrick Seguin, London

de Carvalho J, Brasilia J (1991) From utopia to reality. Curr Anthropol 32(3): 359-62. http://www.jstor.org/stable/2743791

Demissie F (2017) Colonial architecture and urbanism in Africa. Routledge, New York

Denison E, Ren GY (2006) Building Shanghai: a story of china's gateway. Wiley Academy, Chichester

Diaz P (2004) Historia da Arte Luso Brasileira Urbanicao e Fortificacao. Almedina, Lisboa

Elsheshtawy Y (2004) Planning middle eastern cities. Routledge, New York

Gade DW (1976) The Latin American plaza as a public space. Publication Series (Conference of Latin Americanist Geographers) 5:16-23

Guerrieri PM (2017) Maps of Delhi. Niyogi Books, New Delhi (ISBN-10: 9385285505, ISBN-13: 978-9385285509)

Guerrieri PM (2018) Negotiating cultures: Delhi's architecture and planning from 1912 to 1962. Oxford University Press, New Delhi

King AD (2012) Colonial urban development culture: social power and environment. Routledge, New York

Kostov S (1991) The city shaped: urban patterns and meanings through history. Bulfinch Press, New York

Kuo L (2017) Inside Chengdu: can China's megacity version of the garden city work?. https://www.theguardian.com/cities/2019/feb/04/if-we-have-toleave-we-leave-the-downside-of-life-in-chinas-park-city

Legg S (2007) Spaces of colonialism. Wiley-Blackwell, Oxford

Lehavi A (2017) One hundred years of zoning and the future of cities. Springer, Verlag

MacDonald WL (1986) The architecture of the roman empire: an urban appraisal, vol II. Yale University Press, Yale
Merlin P (1980) 'The New Town Movement in Europe. In: Annals of the American Academy of Political and Social Science 451 (1980): 76-85. http:// www.jstor.org/stable/1043162

Miller M (1983) Letchworth garden city eighty years on', Built Environment (1978-9), no. 3/4 (1983): 167-84. http://www.jstor.org/stable/23286718, p 168

Morris AEJ (1994) History of urban form: before the industrial revolutions. Longman, New York

Morse Richard M (1962) Some characteristics of latin american urban history. Am Hist Rev 67(2):317-338. https://doi.org/10.2307/1843426

Owens EJ (1991) The city in the greek and roman world. Routledge, New York

Rochon TR (1998) Culture moves: ideas, activism and changing values. Princeton University Press, Princeton

Rodriguez R (2005) The foundational process of cities in Spanish America. In: Focus, vol. 2

Rotbard S (2005) White city black city: architecture and war in Tel Aviv and Jaffa. Pluto Press, London

Saalman Howard (1971) Haussmann: paris transformed (planning and cities). George Baziller, New York

Said EW (1978) Orientalism (Pantheon Books, New York, 1978)_Culture and Imperialism (London: Vintage Books, London, 1994)

Silva P, da Silva C (1987) Le Corbusier e o Brasil. Projecto Editora, São Paulo, p 258

Sobin HJ (1994) Veils and Shadows: Le Corbusier in North Africa, 1928-1936. In: Proceedings of the Meeting of the French Colonial Historical Society, (vol. 19, pp 187-199). Michigan: Michigan State University Press

Sorensen A (2006) The making of urban Japan. Routledge, New York

Spivak GC (1999) A critique of postcolonial reason: towards a history of the vanishing present. Harvard University Press, Harvard

Stanislawski D (1946) The origin and spread of the grid-pattern town. Geogr Rev 36(1):105-120. https://doi.org/10.2307/211076

Vernon C (2004) The Griffin Legacy: Canberra the Nation's Capital of the $21^{\text {st }}$ century. Canberra, National Capital Authority, p 32

Vernon C (2006) Canberra: where the landscape is pre-minent. In: Gordon D (ed) Planning twentieth century capital cities. Routledge, New York, pp 130-149

Volwashsen A (2002) Imperial Delhi. Prestel, London

Wilson WH (1994) The city beautiful movement: creating the North American landscape. Johns Hopkins University Press, Maryland

Woolbert R (1932) Italian colonial expansion in Africa. J Mod Hist 4(3):430-445

\section{Publisher's Note}

Springer Nature remains neutral with regard to jurisdictional claims in published maps and institutional affiliations.

\section{Submit your manuscript to a SpringerOpen ${ }^{\circ}$ journal and benefit from:}

- Convenient online submission

- Rigorous peer review

- Open access: articles freely available online

- High visibility within the field

Retaining the copyright to your article

Submit your next manuscript at springeropen.com 